\title{
Sobre la selección del sílex y su aprovisionamiento en el Tossal de la Roca (Vall d'Alcalá, Alicante)
}

\author{
Maria Garcia-Carrillo Ara *, Carmen Cacho Quesada ** \\ Y SERGIO RIPOLL LÓPEZ **
}

INTRODUCCIÓN

Los trabajos que estos últimos años (1989 y 1990) estamos desarrollando en el área del Tossal de la Roca (Vall d'Alcalá, Alicante) (lám. I) se ciñen fundamentalmente al análisis y localización de las fuentes de materia prima dentro de su entorno. Este proyecto se inició en 1989 con la colaboración de varios investigadores, y muy en particular de $\mathrm{M}$. del Pozo, geólogo especialista en materiales silíceos de la Universidad Autónoma de Madrid. Con ellos emprendimos una serie de prospecciones exhaustivas en un área de 4 kilómetros de radio en los alrededores del yacimiento que habian de permitirnos la localización geográfica de los afloramientos, asi como conocer las circunstancias concretas que rodearon el aprovisionamiento (distancias y direcciones recorridas, potencia del afloramiento, facilidad para su extracción, etc.). De esta manera hemos podido tener acceso a una serie de aspectos socioeconómicos sobre los

* Colaboradora en las excavaciones en el yacimiento del Tossal de la Roca.

* Conservadora Jefe de la Sección de Prehistoria del Museo Arqueológico Nacional, c/ Serrano, núm. 13, Madrid, 28001

*** Profesor Titular del Departamento de Prehistoria e Historia Antigua de la Facultad de Geografia e Historia de la Universidad Nacional de Educación a Distancia, c/ Senda del Rey, s/n, 28071 Madrid. 


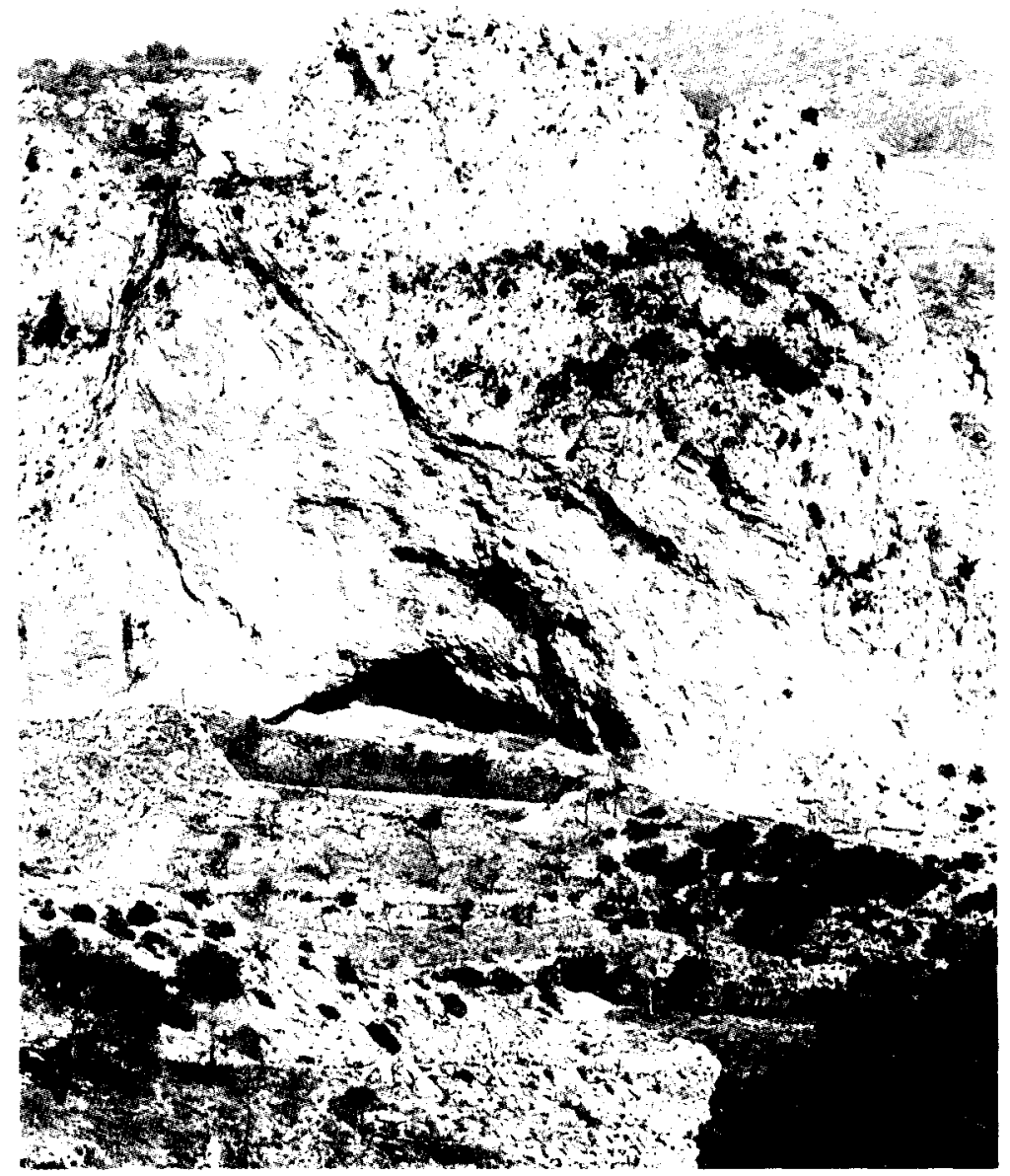

Lamina I. Vista general del abrigo del Tossal de la Roca (Vall d'Alcalá, Alicante) 
habitantes del Tossal, que de ninguna manera habriamos podido conocer simplemente por la excavación del lugar de ocupación.

La base cartográfica empleada en nuestra prospección ha sido la hoja de la zona de Alcoy, a escala 1:50.000, del Mapa Geológico de España (1975) para la determinación geomorfológica y componentes geológicos del terreno, junto con la del Servicio Geográfico del Ejército para la situación general de los afloramientos. Además de su localización estos afloramientos han sido ampliamente muestreados para su posterior análisis en el laboratorio. Asimismo, se han tomado notas de la situación y características de cada tipo de silex, de las circunstancias de los afloramientos dentro de su medio y en relación con las posibles necesidades del hombre paleolítico del Tossal de la Roca. Para ello hemos analizado otros datos tales como la existencia de fuentes de agua en las inmediaciones de los afloramientos silíceos, vías de acceso naturales, y tiempo real necesario para acceder a ellos, asi como para la extracción de cada tipo de silex.

Dentro del área analizada y siguiendo las indicaciones del geólogo que colabora en este proyecto, elegimos como zonas más probables con presencia de silex aquellas en las que en el mapa geológico se indica la existencia de determinados microfósiles siliceos, frecuentemente relacionados con su diagénesis como son los radiolarios, espongiarios y espiculitas. En estas zonas intensificamos las prospecciones. Sin embargo, y como más tarde se verá, sólo resultaron fértiles algunas de estas áreas prioritarias, mientras que se localizaron fuentes en otras zonas que no se habian considerado en un principio y que según el mapa geológico eran poco probables.

Los depósitos de silex que hemos encontrado durante la prospección no siempre aparecen incluidos en una formación, es decir dentro de su roca caja o en posición primaria, sino que también es muy frecuente en esta región la existencia de depósitos de carácter secundario, de los que sabemos que se aprovisionaban directamente los ocupantes del Tossal, y que aparecen en coluviones, terrazas o incluso plataformas con indicios de transporte fluvial. Por otra parte, el sílex es una roca muy heterogénea; su aspecto, textura y composición pueden variar ampliamente dentro de un mismo afloramiento $e$ incluso dentro de un mismo nódulo. Esto explicaría el hecho de que dos piezas del yacimiento talladas en sílex con aspecto muy similar, provengan de diferentes fuentes. Por el contrario, otras con apariencias diversas podrían tener una misma fuente de origen. Pero en estos casos el análisis microscópico junto con otros métodos muy especificos, nos permite aclarar bastante estas circunstancias, analizando comparativamente las muestras de los materiales procedentes 
del yacimiento y las de las fuentes de origen. Además, la observación directa de los afloramientos y en concreto de la variabilidad que en ellos presentan los silex, nos ha ayudado en ocasiones a determinar directamente cual ha sido el origen de una pieza y nos ha sido de gran ayuda a la hora de seleccionar las muestras para analizar de entre los materiales del yacimiento. La observación de esta variabilidad nos ha evitado en gran medida aumentar innecesariamente el número de los tipos de silex que evidentemente aparecen en él, evitando asi estudiar más muestras de las necesarias.

Resumiendo, pues, los objetivos fundamentales de esta prospección han sido:

- Localización de los afloramientos de silex existentes actualmente en la zona.

- Valoración de la situación geográfica, accesibilidad de éstos dentro de su medio y en relación con la situación (geográfico-ambiental) del asentamiento.

- Cuantificación de los distintos tipos de silex disponibles, definición de las posibles variaciones de color, textura y transparencia de aquellos dentro de cada afloramiento.

- Definición del grado de dificultad que ofrecen los distintos tipos de silex para su extracción.

- Reconocimiento de los posibles indicios de acción antrópica en el área de los afloramientos.

- Muestreo de cada "tipo" de silex así como de su roca-caja.

- Definición de los rasgos más característicos de los nódulos o tabletas en bruto: dimensiones, regularidad y peculiaridades de su corteza, entre otros. Este dato resulta especialmente interesante de cara al estudio de las industrias, ya que suelen ser muy escasos los nódulos completos. Más bien éstos suelen aparecer bastante agotados, lo que impide prácticamente la observación de sus rasgos caracteristicos con la consiguiente influencia que éstos hayan podido ejercer sobre la tipologia de las piezas.

\section{UN PRIMER INTENTO DE CARACTERIZACIÓN DEL SILLXX DEL TOSSAL DE LA ROCA}

Muchos y muy variados son los métodos de caracterización e identificación del sílex (petrológico, geoquímico, paleontológico, etc.) y las 
muestras seleccionadas -tanto en los propios afloramientos naturales como entre los materiales de excavación en el abrigo- están siendo actualmente estudiadas por algunos de estos métodos '. Mientras tanto, y a la espera de estos análisis que permitirán una mayor precisión, hemos clasificado los distintos tipos de sílex - al igual que otros investigadores europeos (Morala, A. 1984; Demars, P. Y. 1982)- según los criterios macroscópicos de su zona interna y externa. Este método nos ha servido para establecer a priori los tipos hipotéticos de sílex que tenemos, aunque habrá que comprobarlos en un futuro mediante los otros métodos.

En un primer momento, y tras una primera prospección durante la campaña de 1987, establecimos siete grupos de sílex a partir del análisis de la industria lítica de los cuatro niveles más antiguos (corte interior) del Tossal (CACHO QueSADA, C. 1983). Estos tipos se han visto precisados a partir de los trabajos de 1989 y para la mayoría se ha localizado su fuente originaria.

La descripción de estos tipos y su justificación fue presentada por uno de nosotros en el Congreso del Silex de Burdeos (CACHO QUESADA, C. 1990), por lo que no insistiremos en ello y nos limitaremos a presentarlo en forma de cuadro-resumen (fig. 1).

De todos los tipos diferenciados en esta primera clasificación, sólo algunos fueron localizados durante nuestras primeras prospecciones. $\mathrm{Pa}$ ralelamente un análisis de los materiales del yacimiento nos permitió establecer una serie de consideraciones:

- La existencia de diferentes fases en la cadena operativa de la talla del material lítico según los tipos de silex. Así, entre los silex grises son muchísimas las piezas que presentan cortex, mientras que en los de color marrón escasean y en el tipo melado es casi inexistente. Esto parece indicar que el silex gris fue transportado sin desbastar, en una primera fase de la cadena operativa, lo que hace pensar que su fuente debía estar cercana al yacimiento. Sin embargo el melado debió ser desbastado in situ, junto al afloramiento, y aparece en un estado ya avanzado de la cadena operativa, lo que nos lleva a pensar que su fuente estaba situada a mayor distancia del yacimiento.

- Son muy escasos los núcleos y siempre aparecen bastante explotados. De estos los que no aparecen nunca o en rarísimas ocasiones

Actualmente estas muestras están siendo estudiadas por M. del Pozo (Departamento de Geologia de la Universidad Autónoma de Madrid). 


\begin{tabular}{|c|c|c|c|c|}
\hline I & $\begin{array}{c}\text { COLOR } \\
\text { Blanco a rosa }\end{array}$ & $\begin{array}{l}\text { TRANSPARENCIA } \\
\text { Translúcido }\end{array}$ & $\begin{array}{c}\text { CALIDAD } \\
\text { Blando, fácil de } \\
\text { tallar }\end{array}$ & $\begin{array}{c}\text { LOCALIZACIÓN } \\
?\end{array}$ \\
\hline II & $\begin{array}{l}\text { Melado, ocre, } \\
\text { rojo o negro } \\
\text { por calor }\end{array}$ & Tanslúcido & $\underset{\text { tallar }}{\text { Blando, fácil de }}$ & $\begin{array}{l}\text { Sierra de } \\
\text { Andoches }\end{array}$ \\
\hline III & $\begin{array}{c}\text { Grises a } \\
\text { negro } \\
\text { jaspeado a } \\
\text { veces }\end{array}$ & Opaco & $\begin{array}{c}\text { Duro, dificil de } \\
\text { tallar. } \\
\text { Impurezas }\end{array}$ & $\begin{array}{l}\text { B. del Penegri, } \\
\text { Confluencia B. } \\
\text { de Roches con } \\
\text { B. de la Gleda } \\
\text { (Pos. 2. }{ }^{\text {) }}\end{array}$ \\
\hline IV & $\begin{array}{l}\text { Marrón a } \\
\text { beige (frec. } \\
\text { band.) }\end{array}$ & Criptocristalino & Difícil de tallar & $\begin{array}{l}\text { Vall d'Alcalá } \\
\text { (Pos. 2. })\end{array}$ \\
\hline V & Beige oscuro & Opaco & $\begin{array}{l}\text { Arcilloso, grano } \\
\text { fino, fácil talla }\end{array}$ & $?$ \\
\hline VI & $\begin{array}{c}\text { Marrón a } \\
\text { beige } \\
\text { (veleado) }\end{array}$ & Criptocristalino & $\begin{array}{c}\text { Muy alterado } \\
\text { ¿Oolitos? }\end{array}$ & $?$ \\
\hline VII & $\begin{array}{c}\text { Otros tipos. } \\
\text { Blanco-beige } \\
\text { (escaso) }\end{array}$ & Translúcido & & $?$ \\
\hline
\end{tabular}

Fig. 1. Cuadro-resumen de los tipos de materia prima localizados con anterioridad a estas prospecciones.

son los de sílex marrón o melado; por tanto cabe preguntarse: ¿transportaban estos dos tipos ya en forma de útil retocado o al menos ya desbastados, o es que estos dos tipos de sílex eran aprovechados hasta el extremo de agotar los núcleos? La explicación podría ser que proceden de fuentes bastante alejadas del asentamiento o bien de fuentes poco abundantes en sílex.

- Los utensilios de mayores proporciones y más espesos siempre aparecen realizados sobre silex de color grisáceo. Por el contrario, los elaborados sobre silex de tipo melado son siempre bastante pequeños, generalmente laminares y con frecuencia están retocados, por lo que este tipo parece ser escaso, incluso seleccionado para este fin, mientras que es evidente la abundancia de los grises, cuya fuente de nuevo resulta - al menos aparentemente- como la más abundante o la más cercana a la estación.

- Parece existir una mayor variedad de los tipos de silex entre las piezas retocadas: los tipos más escasos (marrón y sobre todo el melado) 
existen proporcionalmente con mayor frecuencia entre el material retocado, lo que nos induce a pensar en una cierta selección para la confección de determinadas piezas (por ejemplo, el silex melado para puntas y hojitas de dorso).

- Aparentemente no existen variaciones importantes entre los tipos de silex y sus frecuencias de utilización a lo largo de los cuatro niveles del corte interior del yacimiento.

- En general, observamos la presencia de gran cantidad de restos de talla, lo que confirma el uso del yacimiento como taller y el transporte de la materia prima en las primeras fases de la cadena operativa $y$, lógicamente por tanto, desde distancias bastante cortas, a excepción tal vez de algunos tipos, como sería el caso del silex melado.

- La materia prima empleada es casi exclusivamente silex, pero no descartamos la posibilidad de que en algunos casos (escasos) exista caliza silificada, atribución que podremos precisar una vez finalizados los análisis de las muestras.

\section{PROSPECCIÓN Y DESCRIPCIÓN DE LAS FUENTES}

Este es uno de los puntos, en el que partiendo de los presupuestos iniciales, más variación ha sufrido a lo largo de las prospecciones. Nuestro propósito cuando iniciamos el trabajo era cubrir con ellas un área de 10 kilómetros de radio en torno al yacimiento. Esto se decidió debido a que esa es la distancia media estimada que recorre un hombre en una jornada de marcha de unas ocho horas. De constatarse que el sílex de las industrias no procedía, al menos mayoritariamente, del área incluida dentro de ese radio, esto constituiría un dato interesante por si mismo, e iriamos ampliando sucesivamente el radio de la prospección. Sin embargo, ya desde el comienzo el propio terreno nos fue demostrando que esto no resultaba práctico. En primer lugar, debido a to escarpado de la región esta media resultaba inalcanzable en prácticamente todo el terreno, y desde luego variaba enormemente la distancia alcanzada en un mismo número de horas según la dirección seguida. Pero no sólo difiere la distancia alcanzada sino, sobre todo, el esfuerzo invertido en ello, máxime cuando este recorrido hay que hacerlo cargado con varios kilos de silex. Por otro lado, a medida que fuimos localizando afloramientos, observamos que mientras el tiempo que tardábamos en extraer el silex en algunos casos era sólo de algunos minutos, en otros casos - cuando se 
halla incrustado en la roca- podía llevarnos de tres a cuatro horas para conseguir la misma cantidad de silex. Como en definitiva lo que a nosotros nos interesaba era, al menos en un primer momento, localizar las fuentes de materia prima de explotación asequible en una jornada, muy pronto se nos redujo la distancia a prospectar a un área nunca superior a los 4 kilómetros de radio en torno al yacimiento.

En este área hemos podido localizar las fuentes de todos los tipos de sílex encontrados en el asentamiento, a excepción del melado. Todo esto nos demostró que la distancia existente entre la fuente y el yacimiento no es en absoluto significativa en el caso del Tossal, sino que debe ser matizada en cada caso en términos de distancia en kilómetros, en tiempo y duración requerida para su extracción.

A medida que fuimos encontrando las fuentes de silex, comprobamos que éstas se localizaban casi siempre en las vías naturales de paso. Esto nos indujo a intensificar nuestra prospección a lo largo de estas vías. Así en dirección Norte-Sur se encuentra el Barranco del Penegri y el de Molinet, en dirección Este-Oeste tenemos el Barranco de la Gleda, y el de Roches y todo el llano que rodea la población de Vall d'Alcalá.

De cada fuente localizada hemos recogido una serie de datos que a nuestro juicio resultan de interés para este estudio. Estos datos son los siguientes:

1. Situación de la fuente. Se trata de su situación geográfica, determinada por el punto más cercano a la fuente señalado en el mapa.

2. Situación de la fuente en relación con el medio, es decir si se encuentra en un valle, cerro, planicie o ladera. Si se trata de una via natural de acceso, y sino la distancia existente desde el afloramiento hasta la vía natural de acceso más próxima. También se incluye su relación con respecto a la vía de acceso a la costa o a cursos de agua, su visibilidad: por ejemplo, si se localiza fácilmente —en medio de una llanura - o aparece camuflada por el propio relieve, o derrubios de ladera, etc. Se considera además, la visibilidad alcanzada desde el afloramiento y su accesibilidad. Esta última particularidad se cuantifica de dos maneras: en tiempo (tiempo empleado para llegar desde el yacimiento por la via más fácil) y en esfuerzo, ya que dos fuentes pueden alcanzarse en un mismo tiempo, pero el esfuerzo puede ser muy diferente. Finalmente, también se ha tenido en cuenta la presencia o no de agua y la existencia de abrigos en las cercanias. De esta forma, no sólo hemos localizado los afloramientos $y / 0$ depósitos, sino que hemos intentado también obtener una valoración más real y precisa de su localización desde el punto de vista de las necesidades del grupo humano del Tossal. 


\section{Caracteristicas de la fuente}

- Si se encuentra en su roca-caja o se trata de un depósito secundario.

- Si se trata de un afloramiento, habrá que precisar el tipo (falla tectónica, veta, cantera) y su orientación.

- Potencia y dimensiones aproximadas expresadas en centimetros.

- Continuidad del nivel silíceo.

- Color, grado de consistencia y homogeneidad aparente de la roca-caja.

- En el caso de un depósito secundario, la extensión en metros del área aproximada en que aparecen los sílex y el tamaño medio de los fragmentos.

\section{Caracteristicas del silex}

Se ha tenido en cuenta el modo en que aparece (nódulos o plaquetas), su forma y dimensiones, asi como las caracteristicas de su cortex (color y espesor) y de la zona interna (color, transparencia, textura e impurezas del sílex). Cuando los nódulos, o dentro de un mismo nódulo o veta, hay variaciones se ha documentado el dato.

Se ha contabilizado también el tiempo medio invertido en la extracción. Para que estos tiempos puedan compararse, hemos decidido registrar el tiempo medio empleado para extraer una misma cantidad de silex que fijamos en $1 \mathrm{~kg}$ aproximadamente.

También se ha documentado, en el caso que exista, la presencia de restos de talla in situ en el área circundante a cada fuente.

Para facilitar las tareas de documentación de toda su información recogida en el campo, elaboramos una ficha de inventario de la fuentes (fig. 2). Esta ficha está basada en la utilizada por P.Y. Demars para sus prospecciones de fuentes de materia prima en la cuenca del Brive (DEMARS, P.Y. 1982), completándose con otros aspectos de la publicada 


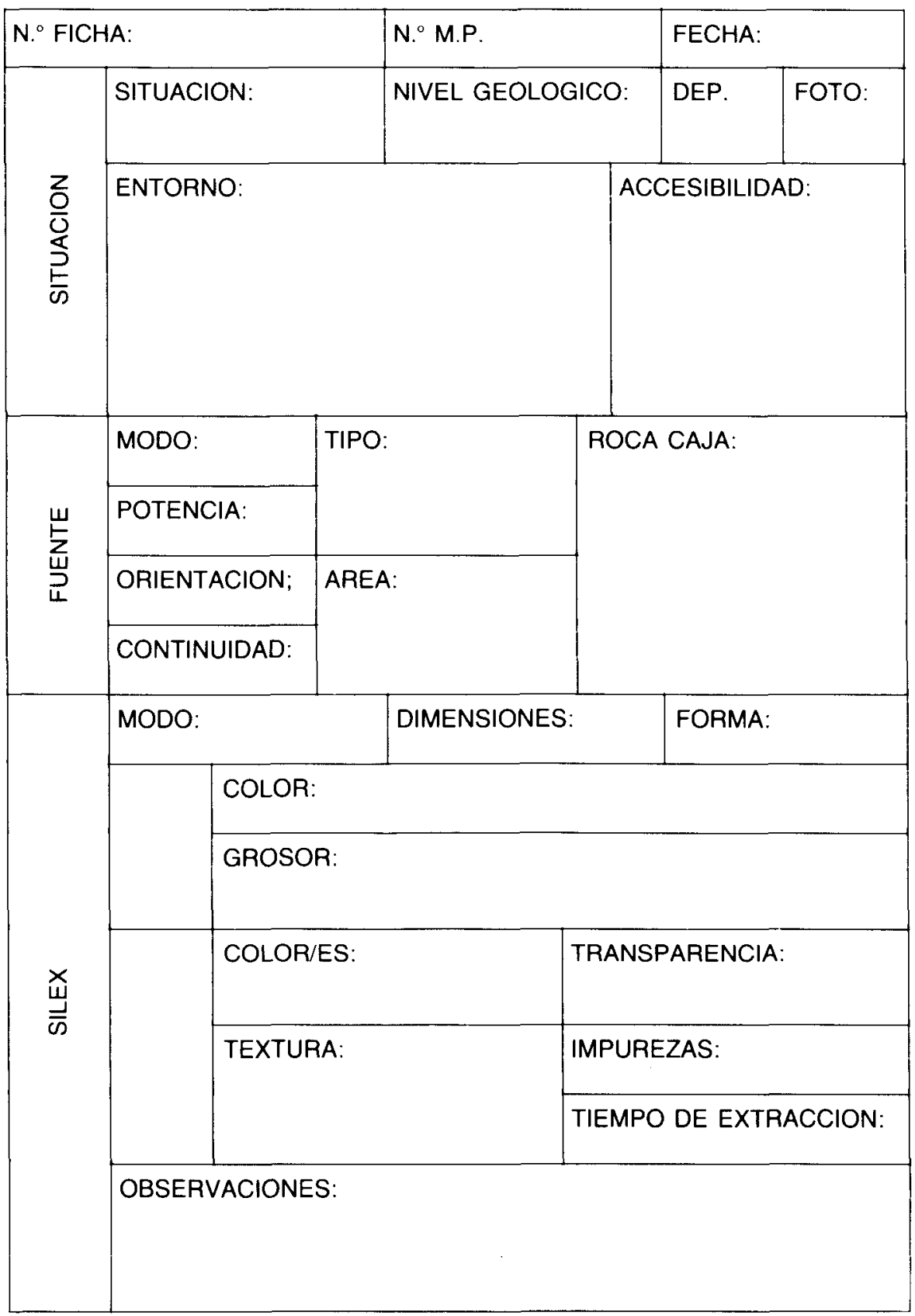

Fig. 2. Ficha modelo para la descripción de las fuentes de materia prima. 
por MALISSEN (1977), así como con datos que hemos observado nosotros mismos durante las prospecciones.

\section{RESULTADOS OBTENIDOS}

Como resultado de las prospecciones realizadas durante estos últimos años hemos localizado las siguientes fuentes (figs. 3 y 4 ).

Fuente n. 1

Este afloramiento se encuentra situado a media ladera de un altozano de unos $100 \mathrm{~m}$ de altura, que se localiza al Oeste del cerro del Molinet y que sobresale totalmente rodeado en su cara Norte por el Barranco de Roches y en el Sur por el de la Gleda (fig. 3).

Son unas vetas calizas que afloran y desaparecen en el suelo, en bandas paralelas que discurren de NE a SW, buzando hacia este último y entre las cuales aparecen de forma muy discontinua los nódulos de silex embutidos en la roca-caja que es de un color gris oscuro, muy homogénea y consistente. El nivel geológico en este punto se corresponde con una mancha de calizas pararrecifales con alveolinas y nunmulites del Terciario (llerdienses), que aflora en este punto entre la biomicritas y las margas indiferenciadas.

Los nódulos son de forma globular, bastante regulares de tamaño, el cual oscila entre los 12 y los $20 \mathrm{cms}$. Presenta un cortex grueso de color gris con algunas zonas amarillentas.

En cuanto a las caracteristicas del silex, éste es siempre translucido, de grano intermedio, y su color es gris bastante homogeneo en algunos nódulos, pero frecuentemente aparece jaspeado por vetas de color rojizo, debido probablemente a una alteración de tipo químico o térmico. El color y la transparencia varía según los nódulos y dentro de ellos, presentando a veces también zonas más opacas.

Este silex presenta gran cantidad de impurezas y es muy duro y difícil de tallar. Su extracción en cambio es bastante fácil. Hemos estimado un tiempo medio de unos quince minutos por kilo. 


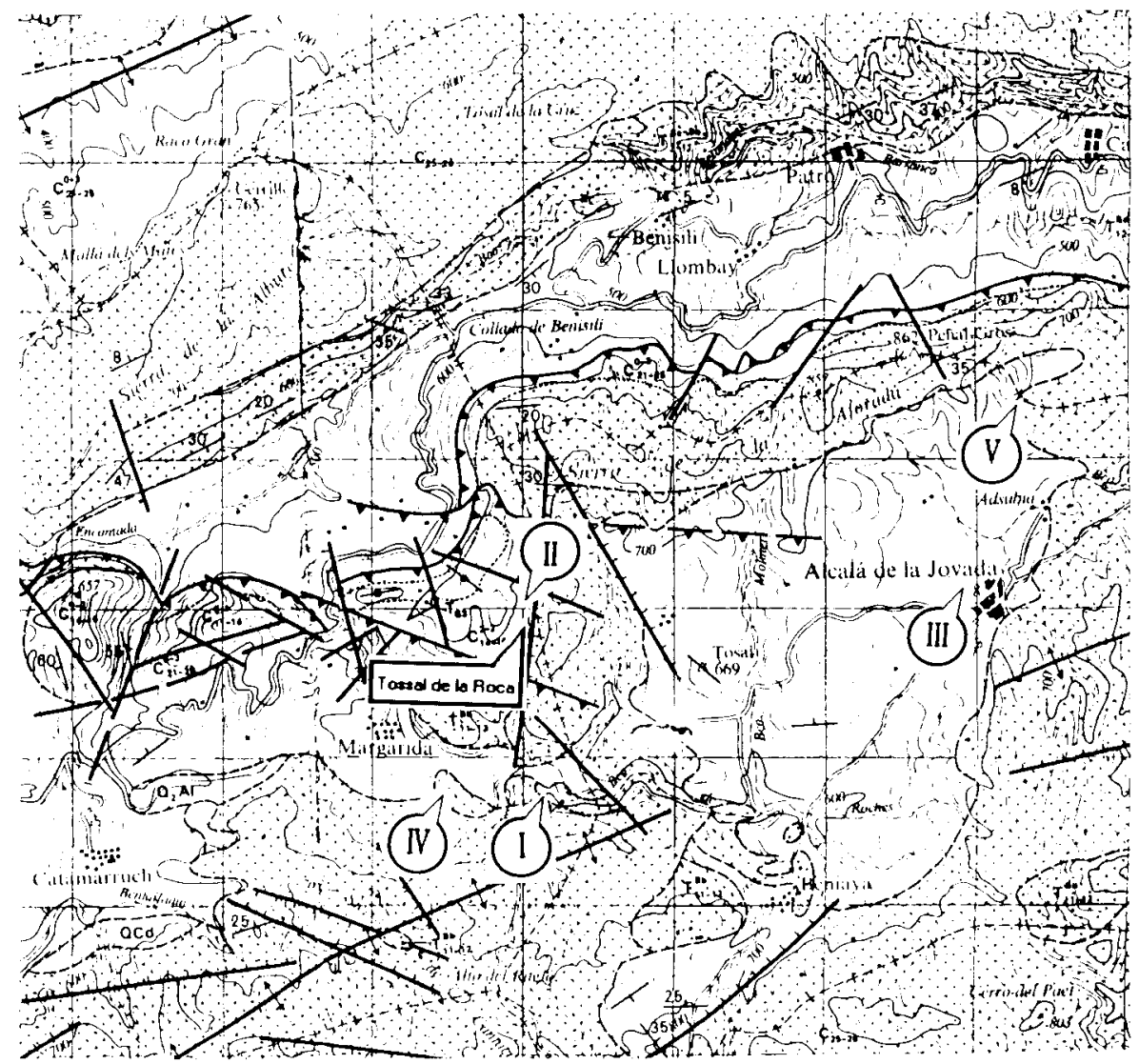

Fig. 3. Localización de las fuentes de materia prima en el mapa geológico de la zona E.: $1: 50.000$. 


\begin{tabular}{|c|c|c|c|c|c|}
\hline 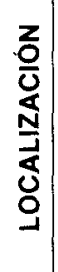 & 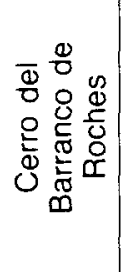 & 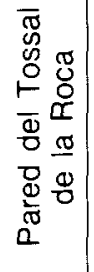 & $\begin{array}{l}\frac{\pi}{\pi} \\
\frac{0}{\pi} \\
\frac{0}{0} \\
\overline{\bar{\pi}} \\
>\end{array}$ & $\begin{array}{l}\frac{\pi}{0} \\
\frac{0}{0} \\
\frac{0}{0} \\
\frac{0}{10} \\
\Sigma\end{array}$ & 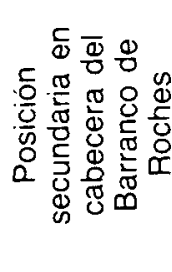 \\
\hline 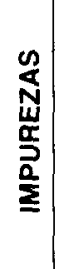 & 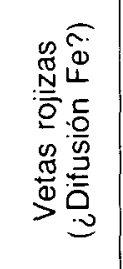 & $\begin{array}{l}\frac{0}{0} \\
\frac{0}{20} \\
\frac{1}{2}\end{array}$ & 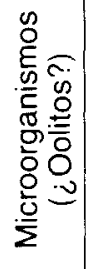 & 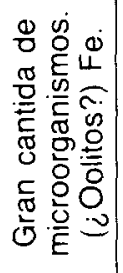 & 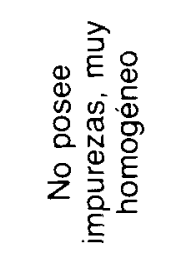 \\
\hline 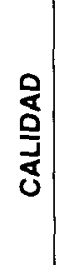 & 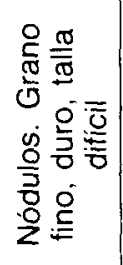 & 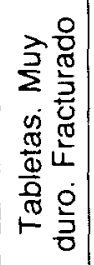 & 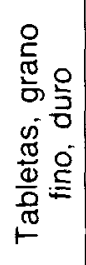 & 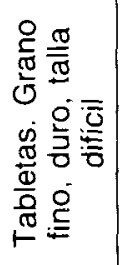 & 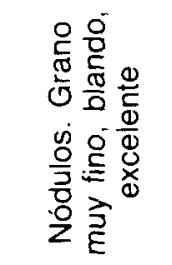 \\
\hline 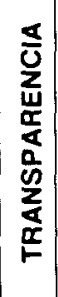 & 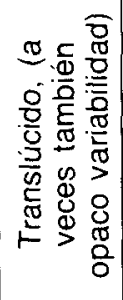 & 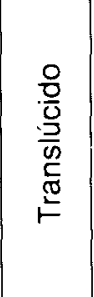 & 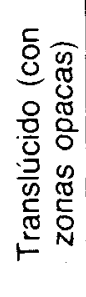 & 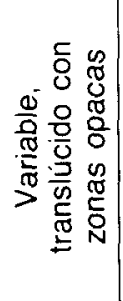 & 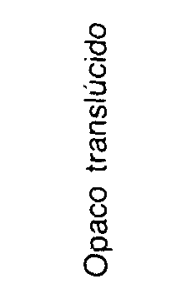 \\
\hline 孚 & 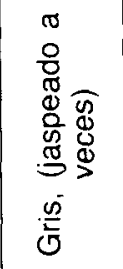 & 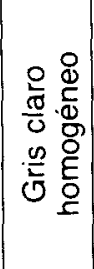 & 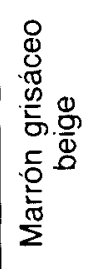 & 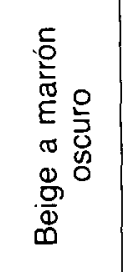 & 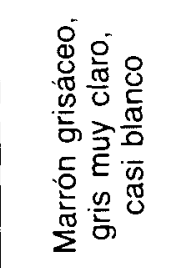 \\
\hline & - & $=$ & $\equiv$ & $\geq$ & $>$ \\
\hline
\end{tabular}


En todo el área del afloramiento hasta la parte baja del cerro y en casi todo el Barranco de Roches, aparece una gran cantidad de fragmentos de este silex. Pensamos, que puede haber sido transportado desde el afloramiento por las escorrentias que descienden por el cerro e incluso por la acción del río, depositándose luego en esta extensa área $\left(500 \mathrm{~m}^{2}\right)$. Entre estos materiales de superficie es muy frecuente encontrar lascas, algunas de ellas retocadas e incluso algunos útiles (localizamos un raspador carenado), lo que parece reflejar una actividad de talla o al menos de descortezado y preparación de los núcleos y útiles in situ.

La situación de este afloramiento es privilegiada desde cualquier punto de vista. Se encuentra a $1 \mathrm{~km}$ del yacimiento, desde donde se puede acceder al cerro a través de la vía natural que es el Barranco de Roches en un tiempo que no excede los veinte minutos y con un esfuerzo mínimo. Desde lo alto del cerro se divisa, además, perfectamente el yacimiento y todo el Barranco de Roches hasta la población actual de Margarida, mientras que desde su cara Sur se domina el Barranco de la Gleda.

En cuanto a la presencia de agua, ésta es muy abundante. Además del río que circula en invierno por el Barranco de Roches, en la base del cerro, por su cara occidental, se localiza una fuente natural de la que fluye agua todo el año.

Fuente $0^{\circ} / 1$

Se encuentra situada en la misma pared caliza vertical en la que está excavado el abrigo del Tossal, a escasos metros del mismo (unos 15 ó 20 metros) (fig. 3).

Se trata de un nivel silíceo de unos $20 \mathrm{~m}$ de longitud y una potencia muy variable, ya que el silex aparece generalmente en tabletas y a veces también en nódulos de forma muy irregular. No se trata de un nivel homogéneo, sino más bien de una especie de "colada silicea", que aparece embutida en una superficie de la pared caliza de unos $50 \mathrm{cms}$ más o menos. El afloramiento es, pues, una falla tectónica (la misma falla que constituye el Barranco del Penegri), que desaparece enseguida, sin que hayamos conseguido localizarlo en otros puntos, en que esta falla caliza aflora. 
La roca-caja la constituyen estas calizas de color gris oscuro a beige amarillento y resulta homogénea, pero bastante alterada por los procesos de gelifracción. La orientación del afloramiento es NW-SE, buzando hacia el Sur. El nivel geológico donde aparece el afloramiento está compuesto por terrenos miocenos indiferenciados, fundamentalmente de margas.

El silex aparece generalmente en tabletas, como mencionábamos antes, aunque a veces existen también nódulos de dimensiones muy irregulares (de 1,5 a casi $50 \mathrm{cms}$ ). Es de tipo criptocristalino, de transparencia muy variable - translucido u opaco, según las zonas-color gris claro y de muy baja calidad, pues presenta muchas impurezas y se encuentra totalmente alterado (craquelado o fracturado), probablemente por la acción de la crioclastía, como ocurre en el resto de la pared caliza. Su grano resulta algo más fino que el que presenta el silex también gris de la fuente $n .^{\circ} 1$, pero al igual que éste es también muy duro y difícil de tallar. Su córtex es una capa caliza muy delgada, de $1 \mathrm{~mm}$ aproximadamente, $y$ de tonalidad gris a gris-beige.

Resulta muy dificil de extraer, hemos calculado que se tarda unos 60 minutos por kilo extraido.

El entorno de la fuente es el mismo que el del yacimiento, es decir en pleno eje de vias de acceso, con una buena visibilidad sobre el Barranco del Penegri y también sobre el inicio del de Roches. Su accesibilidad es buena, ya que está a escasamente un par de minutos del abrigo y se accede sin esfuerzo alguno.

Fuente $0^{\circ} / 1 /$

El afloramiento se sitúa en el llano frente a la actual población de Vall d'Alcalá, en una superficie de unos $100 \mathrm{~m}^{2}$, entre 10 que hoy son bancales cultivados (fig. 3).

Es un silex de color marrón grisáceo oscuro, criptocristalino y translucido en general, aunque algunas zonas adquieren un tono beige claro opaco y posee un grano más grueso. Presenta gran cantidad de microorganismos, sobre todo oolitos. Su córtex es calizo de unos $4 \mathrm{~mm}$ de espesor, de color blanco a beige y aparece muy descompuesto.

La forma en que aparecen son unas vetas paralelas, que se introducen en el suelo en dirección NW-SE buzando hacia el SE. Cada veta tiene una potencia media de alrededor de $12 \mathrm{cms}$. La roca-caja aparece 
totalmente descompuesta, es de color blanquecino y presenta un aspecto de arenisca. En algunos casos la descomposición es tal que se reduce a arenas entre las que aparecen las vetas de forma muy suelta. De esta forma, en muy poco tiempo se pueden extraer varios kilos de silex sin necesidad de ningún objeto punzante.

Este nivel siliceo se localiza en una zona bien visible y con presencia de agua cercana, ya que en sus inmediaciones discurre un riachuelo procedente de la Sierra de la Aforadada, que fluye a lo largo de todo el año, y además junto al afloramiento mismo aparece una surgencia de agua, probablemente de la misma procedencia.

En cuanto a su accesibilidad se encuentra a unos $2,5 \mathrm{kms}$ de Tossal, desde donde se accede fácilmente a la fuente de materia prima, a través del valle de Alcalá, en unos 25 minutos si se va campo a través, pasando un relieve de suaves lomas.

Como en la fuente anterior, la geologia de este punto está compuesta por margas miocenas indiferenciadas. La potencia de este afloramiento es bastante considerable, hasta tal punto que durante los años cuarenta fue explotado por una fábrica de cerámica de Valencia y el material extraído, utilizado como degrasante en sus productos.

Fuente $n^{\circ} \mathrm{IV}$

Se trata de un afloramiento situado al borde de un camino actual que sale en dirección Oeste, unos 2,5 kms antes de llegar a Margarida, caminando por el Barranco de Roches y una vez traspasada la loma donde se sitúa un campo de tiro deportivo (fig. 3).

Aparece en un corte situado en el margen de un camino actual, de unos 7 u $8 \mathrm{~m}$ de altura en su zona de mayor potencia. Aquí la roca se halla hasta tal punto descompuesta, que parece un alto terrizo vertical totalmente blanco, como si se tratase de yeso. En este contexto aparecen varios niveles siliceos paralelos - hasta tres y cuatro- que se extienden, embutidos en este terrizo varias decenas de metros en dirección NW-SE, buzando hacia el SE. Cada uno de estos niveles siliceos o vetas tiene una potencia media de unos $12 \mathrm{cms}$ y presenta una total continuidad.

El silex de este afloramiento es muy característico. Presenta un color que varía desde el beige hasta el marrón oscuro, y a veces marrón rojizo, 
totalmente veteado (de aspecto marmóreo), y tiene una enorme cantidad de impurezas. Son muy numerosos los oolitos. Su córtex calizo es fino $(1-2 \mathrm{~mm})$ y de color blancuzco.

La importante descomposición de la roca-caja facilita la labor de extracción del sílex, y como en el caso anterior, se pueden llegar a obtener varios kilos de material en poco tiempo y no se necesita recurrir al uso de objetos punzantes para ello.

En cuanto a la accesibilidad de esta fuente de materia prima, hay que señalar que se sitúa a unos $2 \mathrm{kms}$ de distancia del Tossal de la Roca, distancia que puede ser recorrida sin gran esfuerzo a lo largo del Barranco de Roches en unos 35-40 minutos. Se sitúa junto a la vía natural de acceso hacia el Oeste, que es el barranco antes citado y presenta una gran visibilidad, dominándose desde allí los profundos cortados que flanquean la población de Margarida por el Suroeste, y hacia el Este los barrancos de Roches y el de la Gleda hasta casi alcanzar con la vista la pared en que se encuentra excavado el Tossal de la Roca. Sabemos, también, de la existencia de una surgencia natural de agua localizada entre estos cortados, al sur del afloramiento, y que desciende por aquellos a unos $200 \mathrm{~m}$ de éste.

El nivel geológico en que se sitúa esta fuente es también un Mioceno indiferenciado en el que predominan, como es habitual en la región, las margas de color blanquecino o verdoso. Sin embargo, dadas las características del terreno, nosotros pensamos que este afloramiento podría estar delimitado por las calcarenitas ferruginosas con presencia de fósiles piritizados, que se extienden por el Cretacico Inferior, y que aparecen también a $1 \mathrm{~km}$ al Norte del pueblo de Margarida.

Fuente $n .{ }^{\circ} \mathrm{V}$

A diferencia de las anteriores en este caso se trata de un depósito secundario de superficie y se sitúa en la parte alta del Barranco de Roches. En él aparecen unos nódulos voluminosos (unos $50 \mathrm{cms}$ de diámetro) que encontramos en el lecho del río, en concreto en el área que rodea al cerro del Molinet y hasta que éste se une con el Barranco del mismo nombre (fig. 3). Los nódulos se encuentran de forma diseminada a lo largo de $1 \mathrm{~km}$ del curso. Prospectamos todo este curso hasta la población de Beniaya y también el Barranco del Molinet hacia el Norte, 
intentando localizar cual podría ser el origen o posición primaria de estos grandes nódulos sin obtener resultado alguno por el momento.

El silex que aqui encontramos, presenta diferentes calidades, así algunos son de color marrón oscuro muy homogéneo, con grano muy fino, opacos, y con un córtex arenoso-calizo muy regularizado por efecto del rodamiento de unos $6 \mathrm{~mm}$ de espesor y color blanco. Este tipo, en particular, es de una gran calidad para ser tallado, pues permite la extracción de unos levantamientos extremadamente netos y no presenta impurezas. Otros nódulos, de semejantes dimensiones y córtex, presentan por el contrario un silex completamente diferente: color gris claro casi blanco, criptocristalino, más duro y menos homogéneo de color, y su talla es mucho más dificil.

Esta fuente se localiza en un angosto barranco más o menos a la altura del yacimiento del Tossal de la Roca (al otro lado del cerro del Molinet). Su acceso puede conseguirse o bien bajando primero por el Barranco del Penegri hasta su confluencia con el de Roches y ascendiendo luego por éste en dirección a Beniaya, lo que supone más o menos $1 \mathrm{~km}$, y unos treinta minutos de recorrido relativamente cómodo, o bien puede ascenderse directamente por el cerro. Esta segunda opción, aunque supone un ahorro de distancia, conlleva más tiempo y un mayor esfuerzo. De cualquier forma, resulta menos visible y su situación es claramente menos estratégica que la de los anteriores afloramientos, ya que no se encuentra en ninguna via natural de acceso. Si se acudia, pues, a esta fuente, debia de hacerse de forma expresamente intencionada. Resulta, por el contrario, un terreno excelente para el acoso de caza y posee también agua abundante.

Estas son las fuentes de sílex que hemos localizado durante nuestra campaña de prospección de 1989, sin embargo conviene hacer hincapié en la presencia de silex en forma de fragmentos o incluso en nódulos aislados prácticamente por toda la zona. Algunos de estos nódulos aparecen, por ejemplo, embutidos en la roca que configura el mismo lecho del río del Barranco del Penegrí y también en el Barranco de Roches en su curso medio, cerca de las "marmitas de gigante" que forma alli el relieve a causa de la erosión fluvial.

Pero estos hallazgos de ninguna manera pueden considerarse como fuentes de aprovisionamiento en sentido estricto, lo que no quiere decir que en un momento determinado los ocupantes del abrigo no hicieran uso de alguno de estos nódulos aislados. 


\section{VALORACIÓN DE LOS RESULTADOS}

En un área que no supera los $4 \mathrm{kms}$ de radio en torno al yacimiento del Tossal de la Roca se han localizado cinco fuentes potenciales de silex. Cuatro de ellas son afloramientos de niveles silíceos y sólo una es un depósito secundario. Se ha detectado también la presencia de nódulos aislados incluidos en las calizas en varios puntos, y en superficie se han recogido fragmentos de este material practicamente por todo el área prospectada. Por lo tanto, y a pesar de no reflejarse en los mapas geológicos, queda probada la existencia de unos potentes niveles siliceos en la zona, lo que ha respondido a lo esperado por nosotros dada la gran cantidad de materiales líticos que aparecian en el yacimiento. Pero ahora tenemos datos que confirman nuestras suposiciones anteriores, y que nos permiten afirmar que la región en la que se sitúa el Tossal presenta unas especiales disponibilidades en cuanto a abastecimiento de silex.

La calidad de estas fuentes de materia prima es, sin embargo, muy variada. (fig. 4). Así, los silex de las fuentes números I y $I I$ además de presentar algunas impurezas, resultan bastante difíciles de tallar por su gran dureza. Mientras que los de la fuente número IV, situada en Margarida, presenta tal cantidad de impurezas y microorganismos que su talla resulta casi imposible, ya que para obtener una pieza de pequeño tamaño es necesario primero localizar, entre múltiples tabletas, una zona en la que el silex sea homogéneo. En cuanto a la fuente de Vall d'Alcalá (número III) presenta un sílex más homogéneo, pero también aparecen oolitos con mucha frecuencia y resulta dura para la talla. Tan sólo la fuente número $V$, el depósito secundario localizado en el Barranco de Roches, resulta adecuado para la talla tanto por su ductilidad como por su calidad y textura.

El microlitismo de la industria del Tossal junto con la gran abundancia de restos de talla que aparecen en el yacimiento y las consideraciones que hemos hecho en torno a la calidad de la materia prima, nos lleva a contemplar la posibilidad de una baja calidad del sílex disponible. Un silex que tan sólo permite el aprovechamiento de una pequeña parte del nódulo. Este hecho encajaria a su vez con la abundancia de materia prima y con el pequeño tamaño de las piezas, a pesar de las grandes dimensiones de los nódulos. También explicaría que no aparezcan núcleos ni piezas con córtex, salvo en el caso del silex gris, ya que si sólo se podia aprovechar una pequeña porción del nódulo para la talla, no tenía sentido transportarlo entero, y muy probablemente se transportaba ya descortezado, y sólo el fragmento apto para la talla. Una excepción 
seria el silex gris, que por su proximidad no merecería la pena descortezarlo in situ, y se tallaria integramente en el yacimiento. De ahi que si bien el tipo gris es el predominante entre los restos de la talla líticos, por el contrario las piezas presentan una mayor variedad de tipos de sílex. Por este motivo, si el microlitismo se debiera sólo a una cuestión cultural o de preferencia, no tendría sentido agotar también tanto los núcleos de silex grises, pues estos los tenian muy próximos a su hábitat y en cantidad abundante. Pero al observar la gran cantidad de impurezas que éstos tienen, entonces sí que adquiere sentido este agotamiento.

Al iniciar nuestro trabajo sobre las materias primas proponiamos unos grupos hipotéticos de silex, que la prospección sobre el terreno ha corroborado en gran medida. En efecto, se han localizado dos afloramientos diferentes de silex de tonalidad beige a marrón, uno de ellos muy alterado y con gran cantidad de oolitos (el que se localiza en Margarida), que se corresponde perfectamente con el descrito en nuestra primera clasificación como tipo seis. El otro tipo (cuatro) posiblemente se corresponda con la fuente que hemos localizado en Vall d'Alcalá. Con respecto al sílex gris se han localizado dos afloramientos, uno en el cerro junto al Barranco de Roches y el otro junto al Tossal. Sin embargo, conviene decir que los silex de ambos afloramientos tienen unas características muy similares, hasta tal punto que resulta imposible su diferenciación si no se conoce su origen. Ambas fuentes se encuentran muy próximas y presentan una roca-caja y orientación similares, lo que nos hace pensar que tal vez se trate de dos afloramientos de un mismo nivel siliceo.

Por último, el tipo $\mathrm{V}$, de color beige, se caracteriza por proporcionar extracciones muy netas y se ha localizado en forma de depósito secundario en el cauce del Barranco de Roches, en el que también aparece el tipo VII, de color blanco y beige.

No se han localizado los orígenes ni del silex de tipo melado (que sabemos que se encuentra fuera del área prospectada: en las cercanias de la población de Muro d'Alcoi), ni del tipo I, de color blanco o rosáceo. Para determinar estos tipos con mayor exactitud habrá que esperar a los resultados de los análisis de las muestras, pero resulta evidente que, gracias a la localización de las fuentes en nuestra prospección exhaustiva de 1989, ahora tenemos más elementos de juicio.

En cuanto a la localización de afloramientos, los resultados han sido muy sugestivos, ya que casi todos los tipos de silex que aparecen en los materiales del Tossal han sido localizados en un radio de $4 \mathrm{Kms}$ en torno al yacimiento. En este sentido, la investigación ha respondido a los resultados obtenidos en la mayoría de los yacimientos europeos, según los 
cuales el silex procede generalmente y salvo excepciones del entorno más inmediato el asentamiento. Otro aspecto interesante que queremos resaltar en este artículo es la localización de estas fuentes. Todos los afloramientos se sitúan junto a cursos de agua, y también todos - a excepción del que está en el Barranco de Roches- se encuentran en zonas de paso o vias de acceso (dirección W-E) hacia la costa. Esta ruta es la más accesible por su situación entre las altas sierras que la flanquean y por ser el camino más corto para llegar hasta la costa. Desde el Barranco de Roches y subiendo a continuación por el Vall d'Alcalá -que discurre entre las sierras de la Aforadada al Norte y del Cireret al Sur- se puede acceder a Pego y de ahí a cualquier punto de la costa entre Denia y Oliva.

Como mencionábamos antes no se han localizado algunos de los tipos de sílex documentados en el yacimiento (el tipo melado y el sílex blanco-rosáceo), por este motivo pensamos que sería de gran interés ampliar el radio de nuestras prospecciones en torno al yacimiento centrándonos fundamentalmente en la zona Este, lugar de paso hacia la costa y área que sabemos era frecuentada gracias al hallazgo de numerosos adornos sobre conchas de origen marino en los niveles de ocupación. 


\section{BIBLIOGRAFIA}

Cacho Quesada, C., 1987: "Nuevos datos sobre la transición del Magdaleniense al Epipaleolitico en el País Valenciano: el Tossal de la Roca». Boletín del Museo Arqueológico Nacional, t. IV/2, Madrid, págs. 116-129.

- 1990: “Un prémier essai d'étude des matières premières du Tossal de la Roca (Alicante, Espagne)". Le Silex de sa genèse à l'outil, Actes de $V$ Colloque International sur le Silex, (Bordeaux 1987), en Cahiers du Quaternaire, núm. 17, Burdeos, págs. 467-470.

Cacho Quesada, C., Fumanal, M. P., López, P. y López, N., 1983: “Contribution du Tossal de la Roca à la chronostratigraphie du Paléolithique Supérieur Final dans la région de Valence". Rivista di Scienze Preistoriche, vol. XXXVIII, Siena, págs. 69-90.

Demars, P. Y., 1982: "L'utilisation du silex au Paléolithique Supérieur: Choix, approvisionnement, circulation. L'exemple du bassin de Brive». Cahiers du Quaternaire, núm. 5, Burdeos, 253 páginas.

MALISSEN, B., 1977: “Elaboration d'une fiche de recensement des gîtes potentiels de matières premières siliceuses". Bulletin de la Societé Préhistorique Française, t. 74, CRSM núm. 7, París.

Mapa Geológico de España, E. 1:50.000, hoja 821. Alcoy, Instituto Geológico y Minero de España. Madrid, 1975, 31 páginas.

Morala, A., 1984: "Périgordien et Aurignacien en Haut Agenais. Étude d'ensembles lithiques". École des Hautes Études en Sciences Sociales. Archives d'Écologie Préhistorique Toulouse. 140 páginas. 